Article

\title{
Relationship between Winter Precipitation in Barents-Kara Seas and September-October Eastern Siberian Sea Ice Anomalies
}

\author{
Jiajun Feng ${ }^{1}$, Yuanzhi Zhang ${ }^{1,2, *}$ and Changqing $\mathrm{Ke}^{3, * \mathbb{D}}$ \\ 1 School of Marine Sciences, Nanjing University of Information Science and Technology, \\ Nanjing 210044, China; fengjiajun093@hotmail.com \\ 2 Center for Housing Innovations, Remote Sensing Group, Chinese University of Hong Kong, \\ Shatin, Hong Kong \\ 3 School of Geography and Ocean Science, Nanjing University, Nanjing 210023, China \\ * Correspondence: yuanzhizhang@cuhk.edu.hk (Y.Z.); kecq@nju.edu.cn (C.K.); Tel.: +852-6995-2064 (Y.Z.)
}

Received: 29 December 2018; Accepted: 6 March 2019; Published: 15 March 2019

\begin{abstract}
In this study, we applied the 1988-2017 monthly average sea ice concentration data from the Met Office Hadley Centre and the 1988-2017 monthly average reanalysis data from the National Centers for Environmental Prediction/Department of Energy (NCEP/DOE) Reanalysis II to analyze the relationship between the winter precipitation in the Barents and Kara Seas (BKS) and the previous autumn eastern Siberian Sea ice anomalies. Through the correlation analysis, we found that the correlation between eastern Siberian Sea ice and the BKS winter precipitation was strongest in September and weakest in November. The results indicated that, when the eastern Siberian Sea ice extent decreased in September-October, a significant positive geopotential height anomaly would occur in the coming winter (December-February) in the Norwegian-Barents region. This result in turn caused anomalies in the northward meridional wind. Consequently, the anomalous water vapor from the mid-latitude Atlantic to the Arctic passed through the Greenland Sea before finally reaching the BKS. The meridional wind also caused the temperature in said seas to increase and the BKS ice to melt, leading to an increase of winter precipitation. We also found that the increase of the Siberian high (SH) in winter was related to the decrease of autumn East Siberian Sea ice extent and the increase of the winter BKS precipitation anomaly. Further research still needs to be refined for this issue in future studies.
\end{abstract}

Keywords: autumn eastern Siberian Sea ice; BKS winter precipitation; water vapor transport; sea ice melt

\section{Introduction}

As one of the most important and fastest-changing regions of the global climate system, sea ice plays a vital role in regulating weather conditions in the region's oceans and the world [1]. However, sea ice has been melting rapidly over the past few decades [2]. Arctic multiyear ice extent $\left(60^{\circ} \mathrm{N}-90^{\circ} \mathrm{N}\right)$, in particular, has dropped sharply at a rate of $9 \%$ per decade [3]. In the 1990s, this decline began to accelerate [4]. The authors of many previous studies have linked the main modes of atmospheric circulation in the northern hemisphere to changes in arctic sea ice [5-7]. Rigor et al. believed that the positive phase of the Arctic oscillation (AO) caused an abnormal decrease in Arctic Ocean sea ice extent in summers. However, Ogi et al. posited that the recent anomalous changes in said ice in September are more closely related to the anticyclone in northern Eurasia in winter and that the relationship between the winter phase AO mode and the summer sea ice was weak [8]. Greenland Sea ice anomalies can also cause atmospheric circulation anomalies in the northern hemisphere. It was found that 
when the spring Greenland Sea ice extent decreased, the geopotential height in the Greenland Sea decreased significantly, which led to low temperatures in the middle and low latitudes of the northern hemisphere [9]. Li et al. reported that the retreat of sea ice in the Kara-Laptev region in autumn caused positive sea-level pressure (SLP) anomalies in the high latitudes of Eurasia in the winter, accompanied by significant positive temperature anomalies and increased precipitation [10]. Honda et al. studied the relationship between sea ice changes off the Siberian coastline in September and the temperature in Eurasia, finding that the continuous reduction of sea ice in September caused Eurasia to be extremely cold [11]. Autumn sea ice extent reduction in arctic regions increases winter snowfall in Greenland, North America, and Eurasia [12,13]. A decrease in Barents-Kara Sea (BKS) ice in autumn and winter leads to a strengthened Siberian High (SH), in turn leading to an abnormal decrease in temperature in eastern Asia [14,15].

The reduction of sea ice also strengthens the local hydrological cycle in that ocean. The Arctic Ocean controls global evaporation and precipitation through these changes. By the end of the twenty-first century, precipitation in the Arctic was predicted to increase by more than $50 \%$ [16]. The increase of arctic region precipitation is closely related to sea ice ablation and rises in temperature. Since arctic precipitation, especially in BKS, is much more sensitive to temperature than in the mid-low latitudes [17], an increase will cause an uptick in snowfall [18]. Increased snow cover in the Arctic $\left(60^{\circ} \mathrm{N}-90^{\circ} \mathrm{N}\right)$ will slow the increase in sea ice by reducing the albedo of arctic sea ice [19]. Increased precipitation in the Arctic Ocean will lead to higher amounts of water vapor, causing the area to warm up and the sea ice to melt [20]. Stroeve et al. analyzed the data for the September sea ice area in terms of arctic cyclone-related precipitation in the autumn, using Japanese 25-year; they found a higher degree of cyclone-related precipitation and water vapor in the Arctic Ocean in high-ice years [21]. However, Miller et al. examined winter Arctic Ocean precipitation, atmospheric circulation, and atmospheric temperature changes through self-organizing maps (SOM), indicating that the large increase in precipitation in the Arctic Ocean was due to increased moisture in the atmosphere, rather than cyclonic changes [22]. The dramatic decrease in the entire arctic sea ice will be accompanied by changes in water vapor transport, which will lead to increased precipitation in the Arctic, especially in September [23]. Atmospheric circulation can dynamically affect the arctic sea ice extent through the surface wind field or through moisture fluxes associated heat flow [24,25]. Yang et al. found that moisture fluxes caused anomalies in the Greenland Sea, which were accompanied by strong surface winds and an increase of the moisture content in the arctic atmosphere, resulted in a decrease in Greenland Sea ice extent [26]. The BKS ice extent in autumn and winter was closely related to the air temperature [27]. Most previous authors looked at the relationship between changes in sea ice and in precipitation across the Arctic.

In this study, we applied the 1988-2017 monthly average sea ice concentration data from the Met Office Hadley Centre and the 1988-2017 monthly average reanalysis data from the National Centers for Environmental Prediction/Department of Energy (NCEP/DOE) Reanalysis II, studied the moisture fluxes related to the BKS winter precipitation, and focused on the impact of Siberian Sea ice conditions in September-October on the BKS winter precipitation.

\section{Materials and Methods}

\subsection{Materials}

\subsubsection{HadISST1 Datasets}

Global monthly average sea ice concentration data from 1988 to 2017 was collected from the Met Office Hadley Centre. The grid resolution of the data set was $1^{\circ} \times 1^{\circ}$. These data sets had high temporal and spatial resolution than other products. By calculating the average of three months, the autumn (September-November) sea ice concentration in the Arctic was calculated $\left(180^{\circ} \mathrm{E}-180^{\circ} \mathrm{W}\right.$, $60^{\circ} \mathrm{N}-90^{\circ} \mathrm{N}$ ). Sea ice extent was defined as the sum area of the grid points, where the sea ice concentration was greater than $15 \%$. 


\subsubsection{NCEP/DOE Reanalysis Data}

The monthly average reanalysis data from 1988 to 2017 was collected from the National Centers for Environmental Prediction/Department of Energy (NCEP/DOE) Reanalysis II. The data included geopotential height, ice concentration, meridional wind, zonal wind, air temperature, and outgoing long-wave radiation (OLR). They were 17 layers of data sets (i.e., 1000, 925, 850, 700, 600, 500, 400, $300,250,200,150,100,70,50,30,20$, and $10 \mathrm{hpa}$ ). As moisture flux was concentrated in the lower atmosphere below $850 \mathrm{hPa}$, the dataset at $850 \mathrm{hpa}$ was used in the study. The grid resolution was $2.5^{\circ} \times 2.5^{\circ}$.

\subsubsection{Global Precipitation Climatology (GPC) Monthly Dataset}

Monthly global precipitation climatology (GPC) data from 1988 to 2017 was also collected in the study. The grid resolution was $2.5^{\circ} \times 2.5^{\circ}$. By calculating the average of three months, the winter precipitation data in December-February was obtained in the Barents-Kara Sea (BKS at $20^{\circ} \mathrm{E}-60^{\circ} \mathrm{E}$, $\left.72^{\circ} \mathrm{N}-84^{\circ} \mathrm{N}\right)$. The GPC precipitation data set was acquired from a combination of microwave and infrared remote sensing data.

\subsubsection{AO Index and NAO Index}

The monthly average AO index and NAO (North Atlantic oscillation) index were used in the study from the National Oceanic and Atmospheric Administration/Climate Prediction Center, in which the winter (December-January-February) average index was calculated as the 3-month average.

\subsection{Methods}

\subsubsection{Correlation Analysis}

The Pearson correlation coefficient was used to calculate the linear relationship between sea ice and precipitation, and we used Student's $t$ test to test the statistical significance of the correlation between different parameters [28]. To eliminate the influence of data fluctuations on the correlation coefficient, we subtracted a least squares fitting line from the data before calculating the correlation coefficient, so the mean value of the detrended data was zero.

\subsubsection{Statistical Significance}

Student's $t$ test was used to assess the level of statistical significance of the results. Results above $90 \%$ confidence were significantly marked as significant.

\subsubsection{Mean Composite Analyses}

In the mean composite analysis, the nonlinear signal not found in linear regression was amplified and the data noise was reduced.

\subsubsection{Mann-Kendall Test}

The Mann-Kendall (M-K) test is a climate diagnosis and prediction technique. The M-K analysis was used to determine whether there was a mutation point in the time series. If there was a mutation point, the time of the mutation was determined $[29,30]$.

\section{Results}

\subsection{The Winter Precipitation Anomalies in the Barents-Kara Sea}

Using the monthly GPC precipitation data, the winter (December-February) precipitation anomalies were calculated in the Barents-Kara Shelf Sea (BKS) region $\left(20^{\circ} \mathrm{E}-60^{\circ} \mathrm{E}, 72^{\circ} \mathrm{N}-84^{\circ} \mathrm{N}\right)$ from 1988 to 2017. As shown in Figure 1, the BKS precipitation was largest in 2004, but it was smallest in 2000. 
Applying the M-K test, we found that 2003 was a mutation point. That is, the average precipitation from 1985 to 2003 was greatly different from that from 2004 to 2017. In 2003, precipitation in the BKS transitioned from negative anomalies to positive ones, based on the thirty-year average from 1988 to 2017; before that year, the precipitation in the BKS was below the 30-year average, while after it was higher than the 30-year average. Panagiotopoulos et al. found that the Siberian high (SH) showed a sharp decline from 1975 to 2000, and in 2000 the trend reversed [31]. The winter BKS precipitation trend shown in Figure 1 also reversed in 2000. The relationship between winter BKS precipitation and winter SH from 1979 to 2017 will be explained in the discussion section

Figure 1 also shows that the precipitation from 1995 to 2000 in the Barents-Kara Seas decreased rapidly, but this trend did not pass the said test.

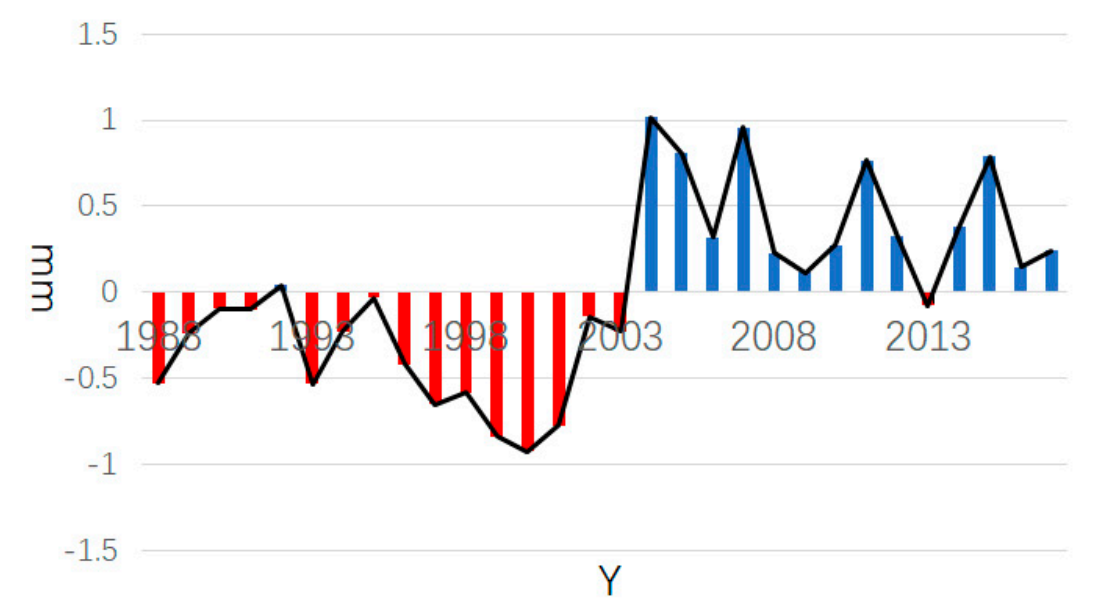

Figure 1. Winter precipitation anomalies in the Barents and Kara Seas from 1988 to 2017, unit: mm.

\subsection{Autumn Eastern Siberian Sea Ice Affecting the Winter BKS Precipitation}

Using the Hadley monthly sea ice concentration dataset, we estimated the autumn eastern Siberian Sea ice extent. To explore the relationship between said extent and the winter Barents-Kara Sea precipitation, the correlation coefficient between the two was calculated. Before the correlation analysis, all the data were de-trended.

Figure 2a shows the correlation coefficient mentioned. The colored regions passed the $t$ test at $90 \%$ confidence. A negative signal in the eastern Siberian Sea was clearly seen (near $130^{\circ} \mathrm{E}-180^{\circ} \mathrm{E}$, $72^{\circ} \mathrm{N}-80^{\circ} \mathrm{N}$ ). This indicated that the melting of the autumn eastern Siberian Sea ice was related to an increase in winter precipitation in BKS. The eastern Siberian Sea is one of the arctic marginal seas, in which the ice changes dramatically. In September, the eastern Siberian Sea ice was at its smallest extent. A decrease in autumn eastern Siberian Sea ice extent was observed to an increase in Siberian High (SH) SLP, which in turn caused the Eurasia and East Asian high latitudes to cool [30]. In addition to eastern Siberia, a weak negative signal was seen in Novaya Zemlya (near $60^{\circ} \mathrm{E}, 72^{\circ} \mathrm{N}$ ), while a weak positive signal was found in the Parry Islands (near $120^{\circ} \mathrm{E}, 82^{\circ} \mathrm{N}$ ). To verify the negative relationship between the autumn eastern Siberian Sea ice and the winter precipitation in the BKS, we calculated the correlation coefficient between the NCEP/NCAR autumn sea ice concentration and BKS winter precipitation (Figure 2 b). There is a negative signal only in the eastern Siberian Sea, with those in other sea areas disappearing. 


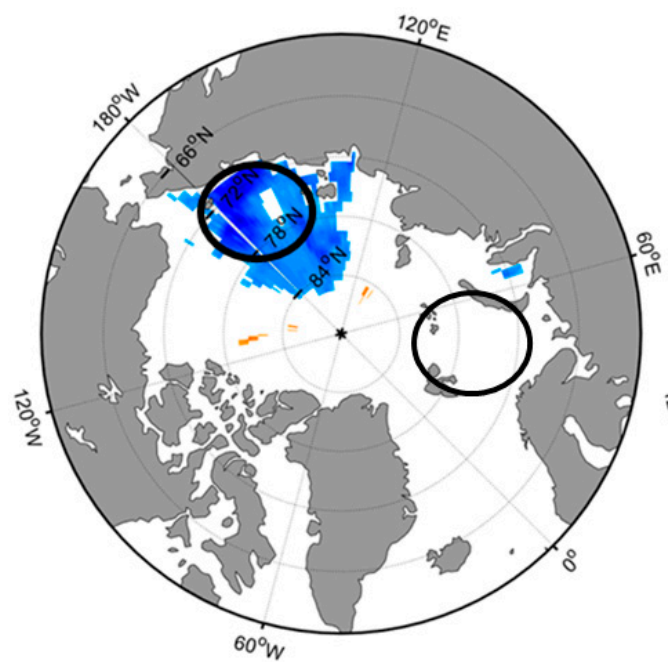

(a)

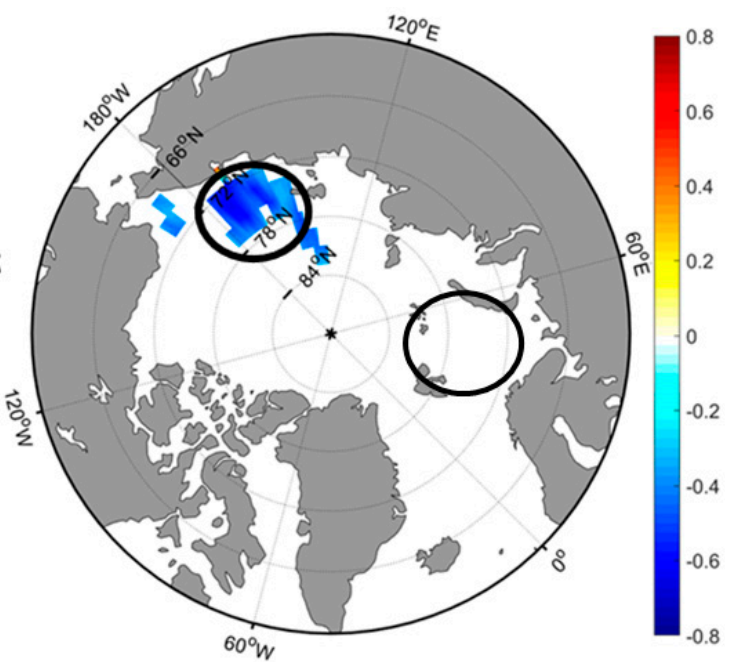

(b)

Figure 2. Correlations between autumn arctic sea ice extent and winter Barents-Kara Seas (BKS) precipitation with two data sets: (a) Hadley sea ice concentration data set; (b) National Centers for Environmental Prediction/Department of Energy (NCEP/DOE) sea ice concentration data set. Note the negative correlation indicated by blue in the circled EES (eastern Siberian Sea) region and white in the circled BKS region. All the data have been de-trended.

To study the effects of the autumn eastern Siberian Sea ice on winter precipitation of the BKS, we chose August, September, October, and November as the relevant months to calculate the relationship between the two. Through calculations, we found that the September eastern Siberian Sea ice concentration had the greatest impact on winter precipitation in said sea. Figure 3 shows the distribution of correlation coefficients between BKS winter precipitation and eastern Siberian Sea ice in August, September, October, and November. First, in August (Figure 3a), the negative correlation area appeared in the eastern Siberian Sea, but this only covered a small region, showing a discrete distribution. In September (Figure 3b), the negative correlation area still appeared in the eastern Siberian Sea, and the negative signal area extended to the north, with the coverage area reaching the maximum. In October (Figure 3c), the negative correlation zone in the eastern Siberian Sea began to dissipate, only covering the marginal eastern Siberia sea. In November (Figure 3d), the negative correlation zone of the eastern Siberian Sea was completely dissipated. The eastern Siberian Sea is an arctic marginal sea, and August and September are periods of dramatic changes in ice in this sea, with it retreating rapidly. In October, the sea ice of said sea was in the icing period and changed relatively little. In November, the eastern Siberian Sea ice froze and barely changed. We defined the autumn eastern Siberia sea ice extent anomalies (the black area in Figure 2, near $130^{\circ} \mathrm{E}-180^{\circ} \mathrm{E}$, $72^{\circ} \mathrm{N}-80^{\circ} \mathrm{N}$ ) in September-October (Sep-Oct) from 1988 to 2017 as the sea ice index. The standard deviation of the sea ice index was used as a threshold. When the index was higher (lower) than one standard deviation, we used it as a high- (low-)sea ice index year. Therefore, the high-sea ice index years were 1988, 1992, 1994, 1996, 1997, 1998, and 2001, while the low-sea ice index years were 2007, 2008, 2012, and 2016. 
(a)

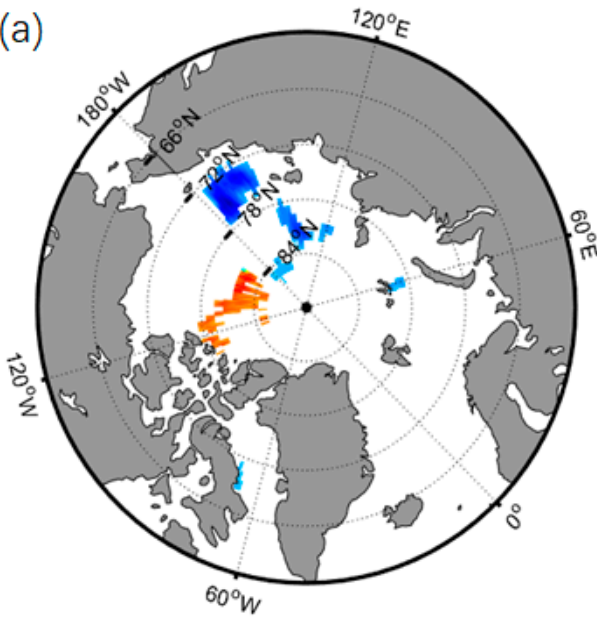

(c)

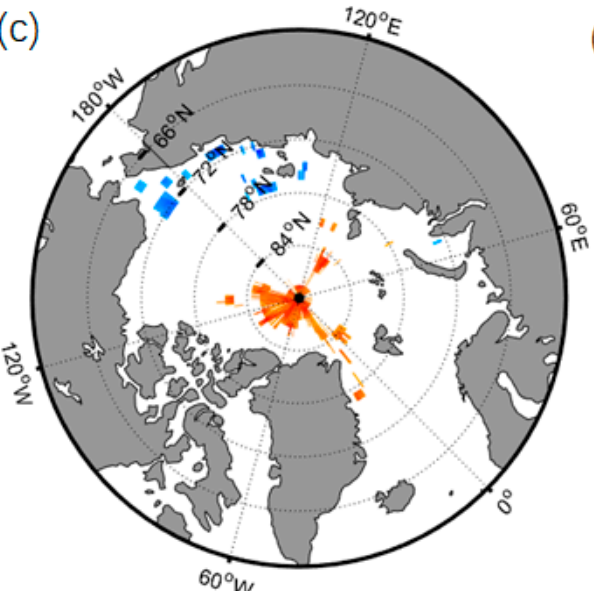

(b)

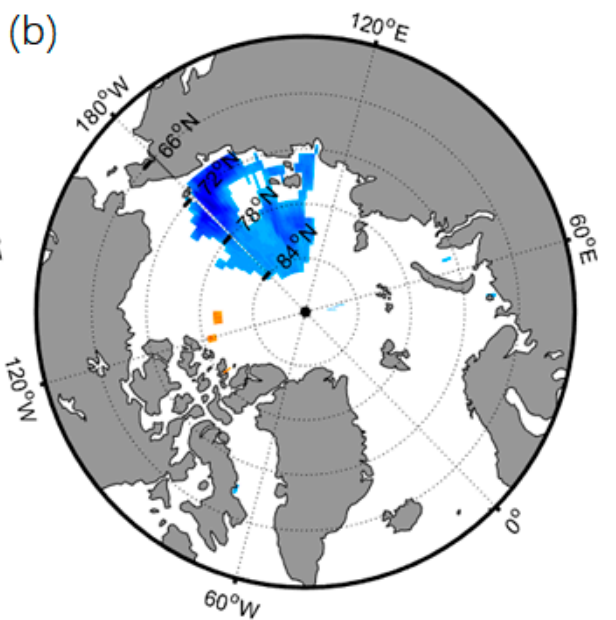

(d)

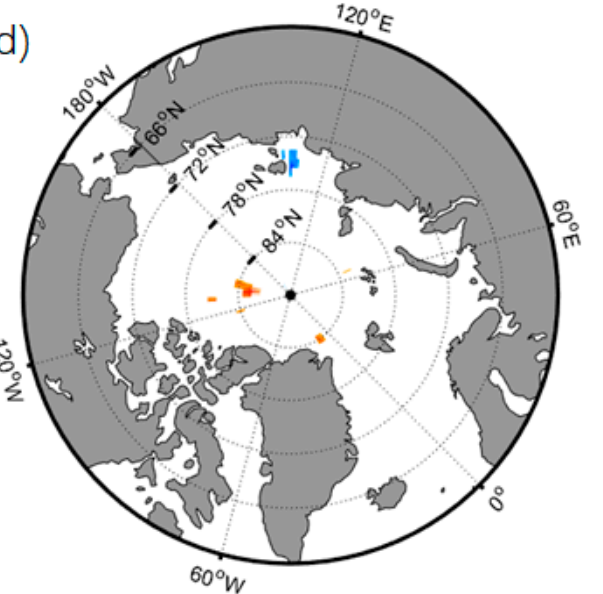

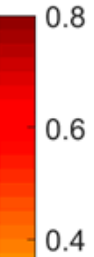

0.2

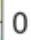

$-0.2$

$-0.4$ $-0.6$

Figure 3. The correlation coefficient distribution between the winter precipitation of the Barents-Kara Sea and the autumn sea ice in August (a), September (b), October (c), and November (d). All the data have been de-trended.

\subsection{Winter Atmospheric Circulation Anomalies Associated with Autumnal Eastern Siberian Sea Ice Extent Anomalies}

In the previous sections, we detailed the relationship between the autumnal eastern Siberian Sea ice anomalies and the BKS winter precipitation anomalies. To explore their relationship, we used mean composite and correlation analyses to investigate the correlation between the autumn eastern Siberian Sea ice extent and the winter atmospheric circulation activity in the northern hemisphere. Figure 4a shows the correlation coefficient between the autumn eastern Siberian Sea ice extent and the winter SLP (sea-level pressure) in the northern hemisphere. The colored regions passed the $t$ test at $90 \%$ confidence. The autumn eastern Siberian Sea ice extent was negatively correlated with the winter SLP, indicating that when the Siberian Sea ice extent was reduced, a clear positive SLP anomaly existed in the Norwegian-Barents Sea that extended to Siberia through Eastern Europe. Figure $4 \mathrm{~b}$ shows the correlation coefficient between the autumn sea ice index and the $500 \mathrm{hpa}$ winter geopotential height. As seen in Figure 4 b, compared with Figure $4 a$, the geopotential anomaly was highly concentrated in the Norway-Barents region. At the same time, the geopotential height anomalies in the Beaufort Sea, with the reverse phase of Norway-Barents, were found. The winter Norway-Barents-centered SLP (500 hpa geopotential height) anomaly (black part, $0^{\circ} \mathrm{E}-60^{\circ} \mathrm{E}, 60^{\circ} \mathrm{N}-75^{\circ} \mathrm{N}$ ) was calculated. 


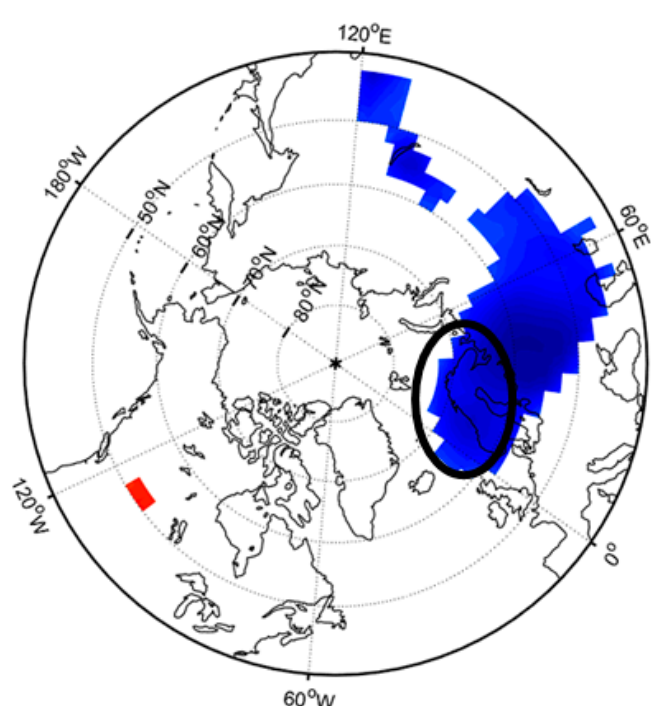

(a)

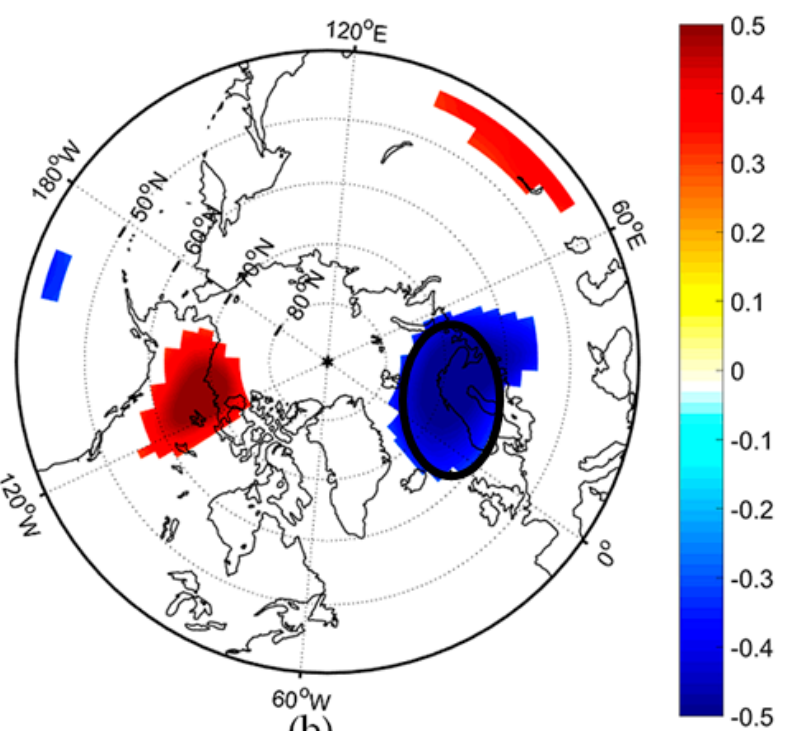

(b)

Figure 4. (a) Correlation coefficient distribution between sea ice index and sea-level pressure (SLP);

(b) 500-hpa geopotential height. The colored regions passed the $t$ test with a confidence level of $90 \%$.

All the data have been de-trended.

To explore the relationship between the autumn eastern Siberian Sea ice extent and the winter atmospheric circulation in the northern hemisphere, we also calculated the correlation coefficient between the two in winter. As shown in Table 1, the correlation coefficient between the Sep-Oct eastern Siberian Sea ice and the winter Siberian High $(\mathrm{SH})$ was -0.5 , and the absolute value was much higher than the correlation coefficient between the Sep-Oct eastern Siberian Sea ice and the winter AO (arctic oscillation) $(\mathrm{R}=0.30)$. Table 1 demonstrates that the relationship between the eastern Siberian Sea ice extent and the winter NAO index in Sep-Oct was very weak $(R=0.07)$. The correlation between the winter $\mathrm{AO}$ and winter $\mathrm{SH}$ was also very weak $(\mathrm{R}=-0.19)$. In addition, we calculated the relationship between $\mathrm{SH}$ and NAO (North Atlantic oscillation) with a correlation coefficient of 0.14 . Table 2 shows the correlation coefficient between the BKS winter precipitation anomalies $\left(20^{\circ} \mathrm{E}-60^{\circ} \mathrm{E}\right.$, $72^{\circ} \mathrm{N}-84^{\circ} \mathrm{N}$ ) and the main atmospheric patterns of the northern hemisphere in winter. As shown in Table 2, a strong positive correlation existed between winter SH and BKS winter precipitation, but the positive correlation between $\mathrm{BKS}$ winter precipitation and $\mathrm{AO} / \mathrm{NAO}$ was very weak, suggesting that winter SH played a greater role than $\mathrm{AO} / \mathrm{NAO}$ in $\mathrm{BKS}$ winter precipitation: $\mathrm{SH}$ was closely negatively related to autumn eastern Siberian Sea ice extent and positively related to the BKS winter precipitation anomaly. These relationships will be explained in detail in the discussion section.

Table 1. Correlations between the autumn sea ice index and the winter arctic atmospheric circulation. Correlation coefficients over $90 \%, 95 \%$, and $99 \%$ confidence levels are represented by ${ }^{*}{ }^{* *}$ and ${ }^{* * *}$, respectively. DJF is December-January-February, $\mathrm{SH}$ is Siberian high, AO is arctic oscillation, NAO is North Atlantic oscillation.

\begin{tabular}{cccc}
\hline & Sep & Oct & Sep-Oct \\
\hline DJF SH & $-0.50^{* * *}$ & $-0.50^{* * *}$ & $-0.50^{* * *}$ \\
DJF AO & 0.24 & $0.31^{*}$ & $0.30^{*}$ \\
DJF NAO & 0.04 & 0.11 & 0.07 \\
\hline
\end{tabular}


Table 2. Correlation between the winter Barents-Kara sea precipitation anomalies and winter arctic atmospheric circulation. Correlation coefficients over $90 \%, 95 \%$, and $99 \%$ confidence levels are represented by ${ }^{* * *}$ and ${ }^{* * *}$, respectively.

\begin{tabular}{cccc}
\hline & NAO & AO & SH \\
\hline $\mathrm{R}$ & 0.08 & -0.04 & $0.58^{* * *}$ \\
\hline
\end{tabular}

Using the northern hemisphere meridional wind data, we calculated the correlation coefficient between the previous autumn eastern Siberian Sea ice extent and winter 850 hpa meridional wind in the northern hemisphere (Figure 5a). The correlation coefficient between winter SLP (500 hpa geopotential height) anomaly centered in the Norway-Barents Sea and the meridional wind at $850 \mathrm{hpa}$ (500 hpa) in winter was also calculated (Figure $5 \mathrm{~b}, \mathrm{c}$ ). The colored regions passed the $t$ test at $90 \%$ confidence. When eastern Siberian Sea ice extent decreased in autumn, a significant positive winter SLP (500 hpa geopotential height) anomaly occurred in the Norwegian-Barents Sea. As a result, south (north) wind anomalies occurred in the Atlantic Ocean (Barents and Kara Sea). As can be seen from Figure $5 b, c$, a south wind anomaly was present in the Atlantic Ocean, which was conducive to the spread of moisture from the mid-low latitudes of the Atlantic to the Arctic. At the same time, north winds were blowing in the BKS. The north wind anomalies could spread the moisture from the Atlantic Ocean to said seas, resulting in increased precipitation in BKS. Figure 5 a also shows similar results.
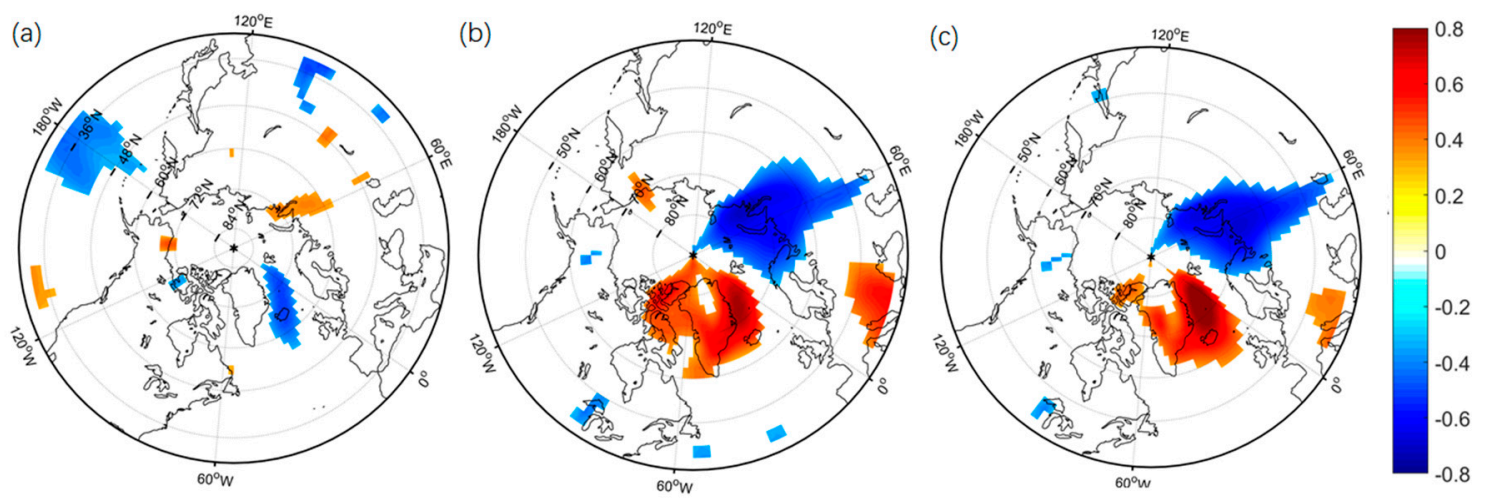

Figure 5. (a) Correlation coefficient distribution between the winter meridional winds in the northern hemisphere at 850 pha and autumn eastern Siberian Sea ice extent; (b) the Norway-Barents-centered SLP in winter; (c) correlation coefficient distribution between the winter meridional winds in the northern hemisphere at 500 pha and the Norway-Barents-centered 500 hpa geopotential height in winter. The colored regions passed the $t$ test with a confidence level of $90 \%$. All the data have been de-trended.

In the 30 years of our available data, it can be observed that the entire arctic sea ice extent has been experiencing a rapid decline in September-October [32]. When the ice melting season was over, the Arctic was more open water than in the previous freeze period; as open water absorbed heat, the sea ice extent decreased compared to that in the previous freeze period [33,34]. Changes in atmospheric circulation can lead to stronger precipitation anomalies or changes in factors associated with such anomalies [23]. To study the relationship between autumn eastern Siberian Sea ice extent and the winter BKS precipitation in depth, we used the 850 hpa water vapor transport anomaly in the high and low sea ice index years.

Figure 6a shows the winter water vapor transport anomaly in the northern hemisphere during the low sea ice index years. As can be seen, a strong transport of water vapor was traveling from the lower latitudes of the Atlantic to the north across the Greenland Sea to the Arctic, before going south to the BKS. Thus, local convection and thermal anomalies were enhanced. This result was similar to that shown in Figure 5. However, the water vapor transport flux in other parts of the Arctic was weak. 
In contrast, Figure $6 \mathrm{~b}$ shows the winter water transport in the northern hemisphere during the high sea ice index years. Water vapor transport in the Atlantic Ocean to the North Pole disappeared, and a water vapor transport stream was moving eastward to Norway from the Greenland Sea.

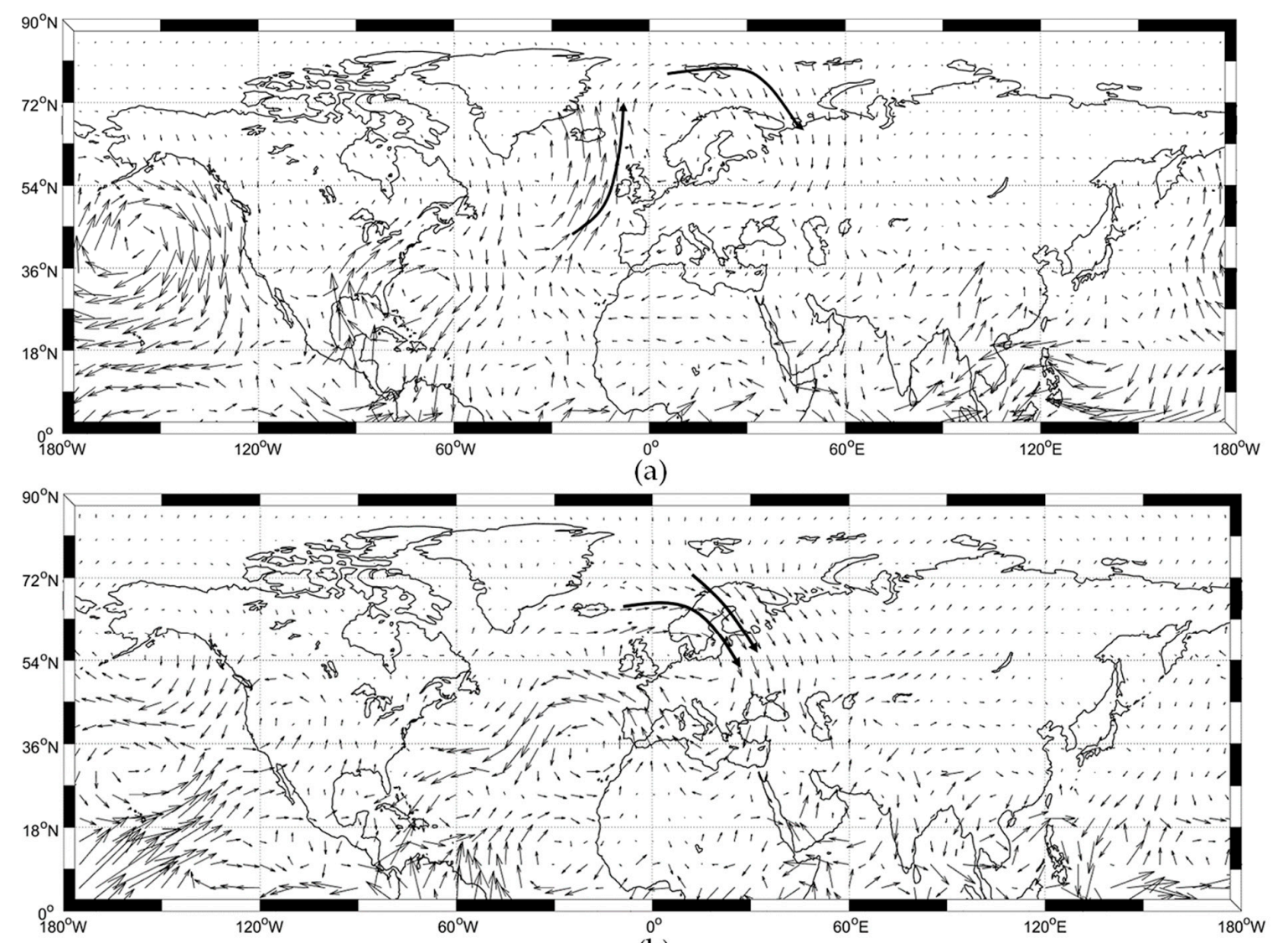

(b)

Figure 6. (a) The winter water vapor transport anomaly in low sea ice index years $(2007,2008,2012$, and 2016); (b) the water vapor transport anomaly in high sea ice index years (1988, 1992, 1994, 1996, 1997, 1998, and 2001).

Figure 7a shows the correlation coefficient between the autumn east Siberian Sea ice extent and 850 hpa meridional winter water vapor transport in the northern hemisphere. Figure $7 \mathrm{~b}, \mathrm{c}$ show the correlation coefficients between winter SLP (sea-level pressure at 500 hpa geopotential height) anomaly centered in the Norway-Barents Sea and the meridional water vapor transport at 850 hpa in winter. The distribution in Figure 7 was similar to that in Figure 6, which further indicated that meridional moisture transport was closely related to meridional wind. When the autumn eastern Siberian Sea ice extent decreased, a significantly positive geopotential height anomaly occurred in Norway-Barents. The south wind anomaly was present in the Atlantic Ocean. This wind carried water vapor into the Greenland Sea, and finally reached BKS through the north wind anomaly, resulting in the increase of winter precipitation in BKS. 

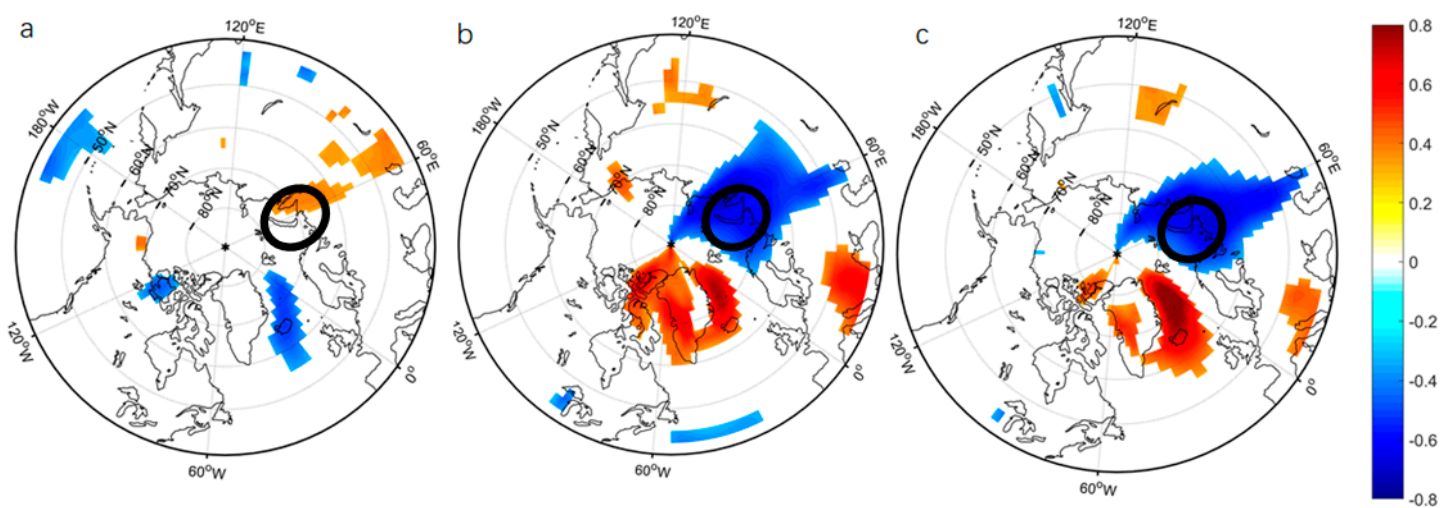

Figure 7. (a) Correlation coefficient distribution between the winter meridional water vapor transport in the northern hemisphere at 850 pha and autumn eastern Siberian Sea ice extent; (b) The Norway-Barents-centered SLP in winter; (c) The Norway-Barents-centered 500 hpa geopotential height in winter. The colored regions passed the $t$ test with a confidence level of $90 \%$. All the data have been de-trended.

\subsection{The Winter BKS Air Temperature Associated with the BKS Winter Precipitation}

Figure 8 shows the correlation coefficient between the meridional 850 hpa water vapor of BKS in winter (the black area in Figure 7 at $20^{\circ} \mathrm{E}-60^{\circ} \mathrm{E}$ and $72^{\circ} \mathrm{N}-84^{\circ} \mathrm{N}$ ) and the winter air temperature at two meters in the northern hemisphere. When BKS meridional water vapor increased, the air temperature in the said seas increased, leading to the melting of the BKS sea ice.

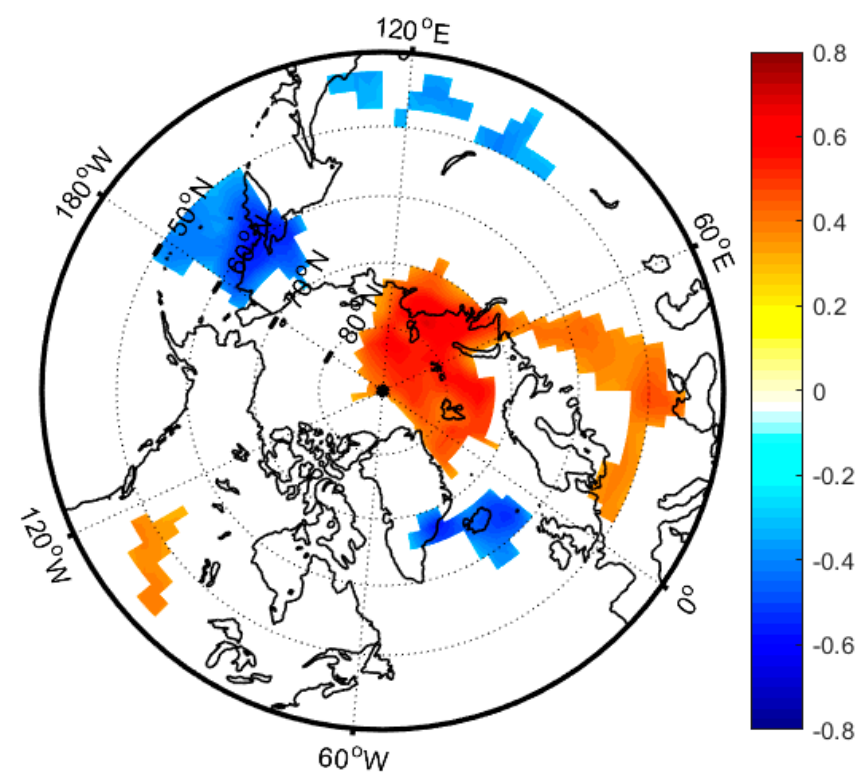

Figure 8. The correlation coefficient between the meridional $850 \mathrm{hpa}$ water vapor of BKS in winter and the winter air temperature at $2 \mathrm{~m}$ in the northern hemisphere. The colored regions passed the $t$ test with a confidence level of $90 \%$. All the data have been de-trended.

According to previous research on the arctic precipitation, increases therein are mainly caused by two factors, one being the melting sea ice of the Arctic and the other being the water vapor transport from the middle-low latitudes [35]. Thus, we calculated the winter air temperature and potential evaporation rate anomalies in the BKS from 1988 to 2017. Figure 9a shows the relationship between air temperature and precipitation in said sea (near $20^{\circ} \mathrm{E}-60^{\circ} \mathrm{E}, 70^{\circ} \mathrm{N}-82^{\circ} \mathrm{N}$ ) with a correlation coefficient of $0.55^{* * *}$. Figure $9 \mathrm{~b}$ shows the relationship between the air temperature and potential evaporation rate in the BKS. The correlation coefficient between them was $0.89^{* * *}$. Such a high correlation indicated that as the air temperature increased, so did the local precipitation and sea ice evaporation in the BKS. 
Bintanja stated that most of the arctic precipitation was caused by water vapor transport in the middle and low latitudes, but as the Arctic warmed, the impact of water vapor transport would become smaller and smaller [17].
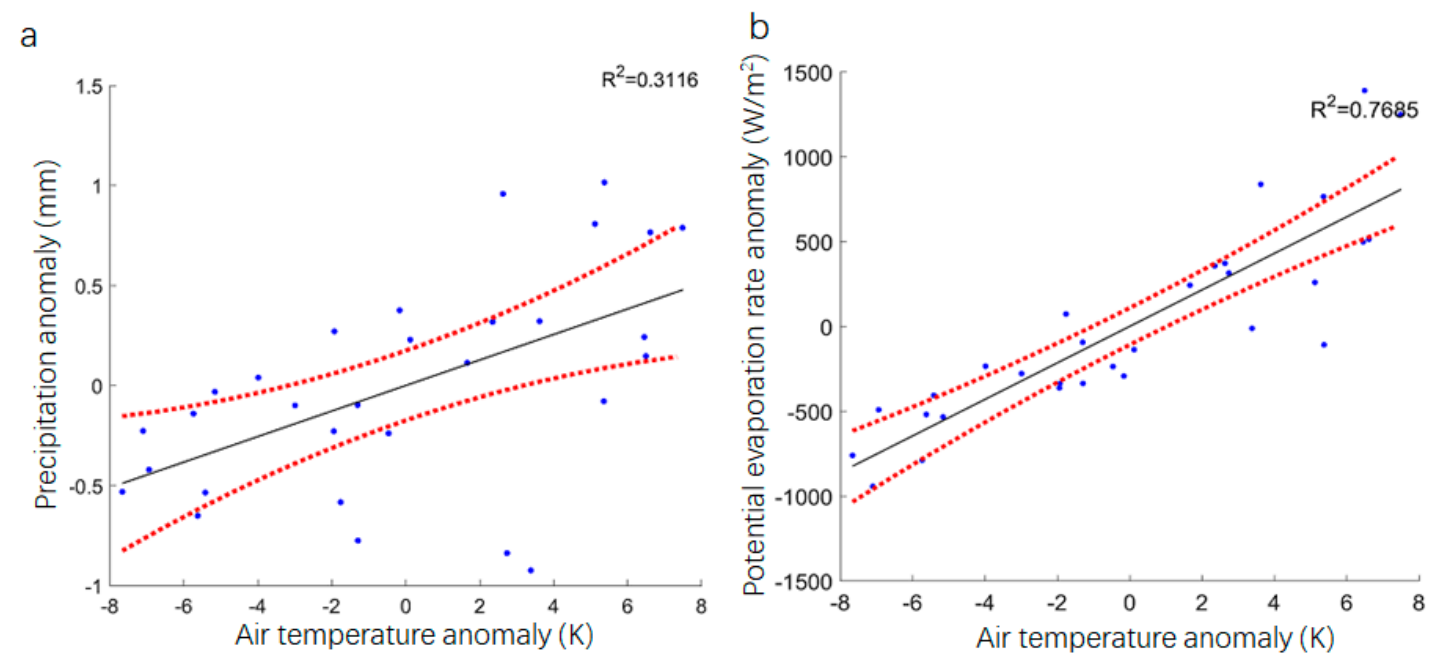

Figure 9. (a) Correlation between winter air temperature anomalies and winter precipitation anomalies in the Barents-Kara Sea; (b) correlation between winter air temperature anomalies and winter potential evaporation rate in the Barents-Kara Sea. The scatter points in the red dashed area passed the $t$ test at $95 \%$ confidence.

To further explore the effect of the winter BKS air temperature on the winter BKS precipitation, we estimated the outgoing long-wave radiation (OLR) anomalies in the low sea ice index years (Figure 10a) and the OLR anomalies in the high sea ice index years (Figure 10b). The black area passed the $t$ test at $90 \%$ confidence. OLR reflects the strength of convective activity and is related to sea surface temperature and cloud cover. In the previous paragraph, we found that a southerly wind existed in the Atlantic that brought warm Atlantic air into the BKS. This may have been one of the factors contributing to the increase in evaporation and temperature in the BKS. As can be seen from Figure 10, both the high- and low-sea ice index years, OLR anomalies were concentrated in the BKS. In the low sea ice index years, OLR showed positive anomalies near the Barents Sea, indicating that the convective activity was enhanced and led to increased water vapor convergence, which was conducive to the local precipitation. In low sea ice index years, the distribution of OLR was reversed. In the Barents Sea, the OLR presented a negative anomaly, and the convection was suppressed, which was not conducive to evaporation and local precipitation. These results further indicate that the evaporation of arctic sea ice will lead to an increase in precipitation in that ocean.

Our analysis showed the following observations: a decrease in autumn eastern Siberian Sea (ESS) sea ice extent was followed by an increase in the winter geopotential height (GPH) over the Barents-Norway seas; this was accompanied by an intensification of southerly meridional winds and increased water-vapor transport into the Atlantic sector of the Arctic. Regional northerly wind anomalies carried heat and moisture further eastward, increasing surface air temperatures in the BKS. Elevated temperatures led to increased evaporation of BKS sea ice and increased winter precipitation in that region. 


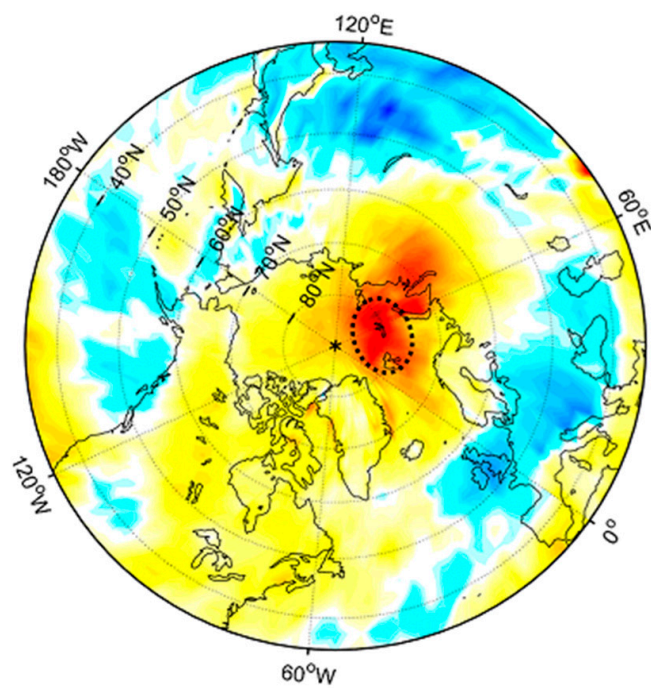

(a)

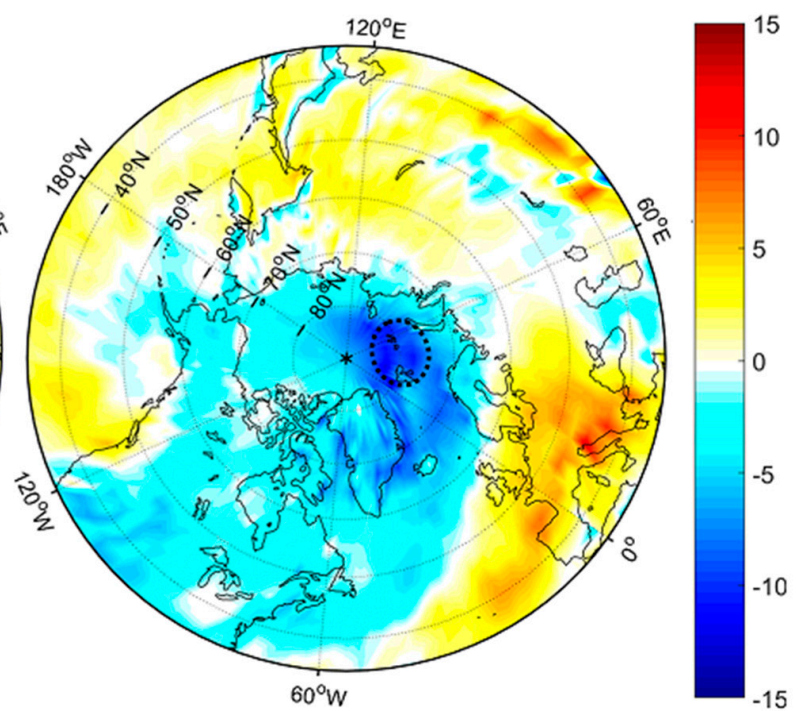

(b)

Figure 10. (a) Outgoing long-wave radiation (OLR) anomaly in low sea ice index years (2007, 2008, 2012, 2016); (b) OLR anomaly in high sea ice index years, unit: $\mathrm{W} / \mathrm{m}^{2}$. The black part passed the $\mathrm{t}$ test at $90 \%$ confidence $(1988,1992,1994,1996,1997,1998$, and 2001).

\section{Discussion}

As seen from Tables 1 and 2, winter SH was closely related to arctic autumn eastern Siberian Sea ice extent and the winter BKS precipitation anomaly. This phenomenon may be caused by water vapor transport. When the autumn eastern Siberian Sea ice extent decreased, especially in September and October, the winter (December-February) water vapor transport increased in BKS, resulting in winter BKS temperature rise and ice melt. The reduction of BKS sea ice in winter will lead to SH strengthening. As reported in [36,37], the decrease of BKS sea ice extent led to the excitation of the Rossby wave, disturbed the polar vortex, and produced a positive geopotential height anomaly extending to northern Europe, which enhanced the high-pressure ridge anomaly near the Ural Mountains. Ridge/trough pattern anomalies and associated near-surface winds would enhance the advection of arctic cold air in the mid-latitudes of Europe and Asia, resulting in the strengthening of Siberian high pressure. In autumn and winter Siberian high Asia, BKS sea ice is closely related to China's air temperature [26,37]. When the eastern Siberia sea ice extent in September-October decreased, cold temperatures would occur in northern China (see Figure 11). This phenomenon may also relate to Siberian high pressure. Before 2000, when the Siberian high weakened, winter BKS precipitation showed a declining trend, but the correlation between winter $\mathrm{SH}$ and BKS precipitation was very weak $(r=-0.064)$. After 2001, the Siberian high was strengthened, and the precipitation of BKS in winter showed an increasing trend, and the correlation between BKS precipitation and SH in winter was strengthened $\left(\mathrm{r}=0.56^{* *}\right)$. Future work will still need to further refine the analysis of the relationship between autumn eastern Siberian Sea ice extent and BKS winter precipitation, addressing their impact on northern China's temperature. 


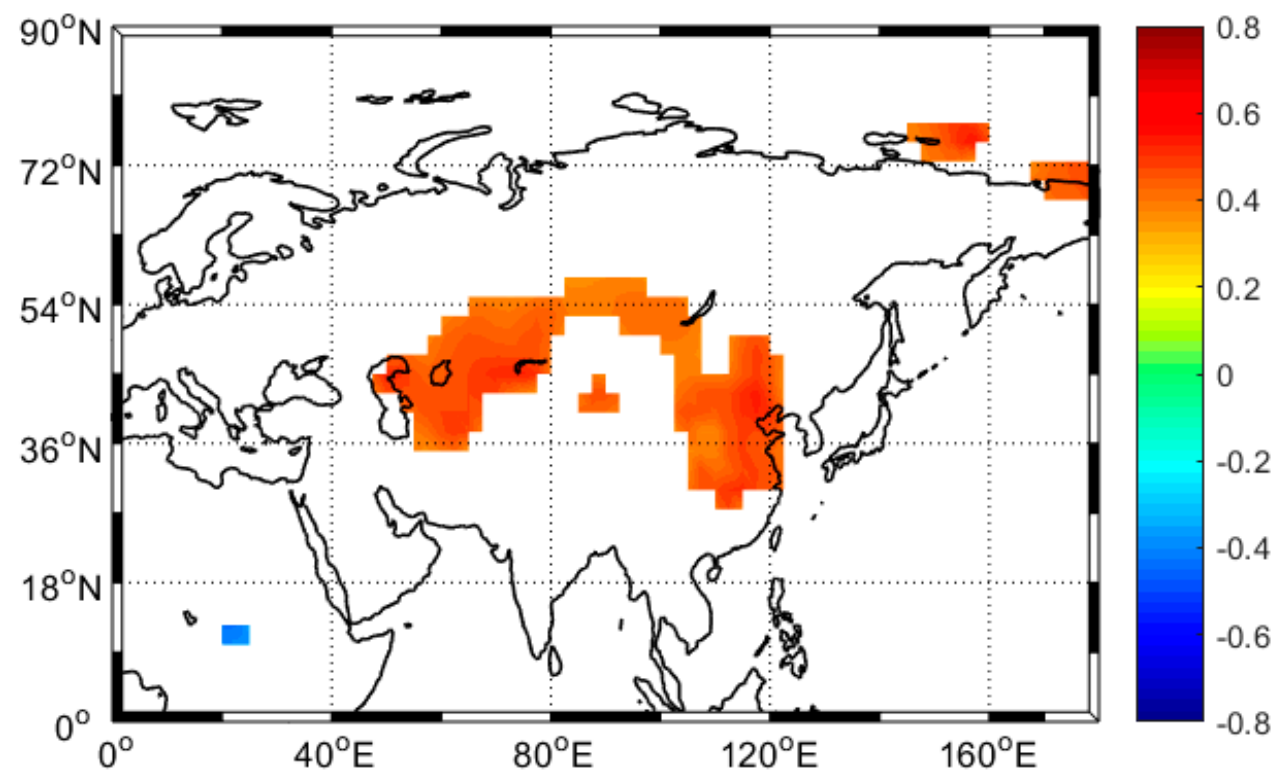

Figure 11. The correlation coefficient between the autumn eastern Siberian Sea ice extent and the winter air temperature at $2 \mathrm{~m}$.

\section{Conclusions}

As a key part of the global climate system, arctic precipitation is of great significance in studying arctic climate change. In this study, we applied the monthly average sea ice concentration data and monthly average reanalysis data to analyze winter precipitation anomalies in the BKS from 1988 to 2017 , finding that precipitation in the BKS has been on the rise for 30 years. Through the correlation analysis, we found that the increase of the sea's winter precipitation was closely related to the decrease of autumn eastern Siberian Sea ice conditions. The September eastern Siberian Sea ice extent has the strongest impact on the precipitation in the Barents and Kara Seas in the winter.

We specially analyzed the Sep-Oct eastern Siberian Sea ice anomaly as the sea ice index. By calculating the relationship between the autumn sea ice index and the characteristics of the main atmospheric circulation in the northern hemisphere, we found that the autumn sea ice anomaly in the eastern Siberian Sea was related to winter SH $(\mathrm{R}=0.5)$. We also calculated the relationship between $\mathrm{SH}$ and arctic precipitation, indicating that the winter $\mathrm{SH}$ is closely related to the winter BKS precipitation.

When the eastern Siberian Sea ice extent decreased in autumn, a significant positive geopotential height anomaly occurred in Norway-Barents in winter, which in turn led to positive atmospheric circulation in the Atlantic Ocean. According to our analysis, the eastern Siberian Sea ice extent decreased in autumn. This decrease preceded a significantly positive geopotential height anomaly over the Norway-Barents (NB) Seas in winter. Following this increase were changes in atmospheric circulation, including a southerly wind anomaly that flows from the mid-latitudes of the North Atlantic, across the Greenland Sea, and toward the North Pole. These winds carry warm, humid air. Simultaneously, an anomalously strong northerly wind blows across the Barents and Kara Seas, eastwardly transporting the moistened air transported from the mid-Atlantic. This results in an increase in both the local precipitation and surface air temperatures of the BKS region.

By calculating the water vapor transport in the low sea ice index years, we found that a positive northward water vapor transportation exists in the Atlantic Ocean. This result is very similar to that of the anomalous wind field in the low sea ice index. In the high sea ice index years, southerly winds in the Atlantic were suppressed, preventing an increase in arctic precipitation. Thus, the strong water vapor transport in the Atlantic Ocean to the North Pole disappeared, and it only reached Norway and spread southward.

The BKS ice evaporation is an important factor, as is water vapor transport. The increase of the meridional water vapor caused an increase in the air temperature near the Barents and Kara Sea. 
We calculated the relationship between the air temperature anomaly near said sea and the precipitation and potential evaporation. The correlation coefficients were 0.55 and 0.87 , respectively. In this case, a strong positive relationship exists between evaporation of the arctic surface and local precipitation. The low sea ice index years featured the positive anomalous distribution of OLR in the anomalous precipitation area, which indicates that the local convective activity leads strongly to the bolstering of local precipitation. Meanwhile, in high sea ice index years, the negative anomaly distribution of OLR in the area of precipitation anomaly inhibited convective activity, which is not conducive to precipitation. This further proves that surface evaporation will lead to increased precipitation. More research work is still needed to refine this issue in future studies.

Author Contributions: Conceptualization, J.F. and Y.Z.; methodology, Y.Z.; software, J.F.; validation, J.F., C.K., and Y.Z.; formal analysis, J.F.; investigation, C.K.; resources, C.K.; data curation, J.F.; writing-original draft preparation, J.F.; writing-review and editing, Y.Z.; visualization, C.K.; supervision, Y.Z. and C.K.; project administration, C.K.; funding acquisition, C.K.

Funding: This research work is supported financially by the Program for National Key R\&D Program of China (2018YFC1407200, 2018YFC1407203), and the Natural Scientific Foundation of Jiangsu Province (BK20181413).

Acknowledgments: The 1988-2017 monthly average sea ice concentration data from the Met Office Hadley Centre and the 1988-2017 monthly average reanalysis data from the National Centers for Environmental Prediction/Department of Energy (NCEP/DOE) Reanalysis II were highly appreciated. This research work is supported financially by the Program for National Key R\&D Program of China (2018YFC1407200, 2018YFC1407203) and the Natural Scientific Foundation of Jiangsu Province (BK20181413).

Conflicts of Interest: The authors declare no conflict of interest.

\section{References}

1. Lemke, P.; Harder, M.; Hilmer, M. The Response of Arctic Sea Ice to Global Change. Clim. Chang. 2000, 46, 277-287. [CrossRef]

2. Bader, J.; Mesquita, M.D.S.; Hodges, K.I.; Keenlyside, N.; Østerhus, S.; Miles, M. A review on Northern Hemisphere sea-ice, storminess and the North Atlantic Oscillation: Observations and projected changes. Atmos. Res. 2011, 101, 809-834. [CrossRef]

3. Comiso, J.C. A rapidly declining perennial sea ice cover in the Arctic. Geophys. Res. Lett. 2002, 29, 17-1-17-4. [CrossRef]

4. Comiso, J.C. Large Decadal Decline of the Arctic Multiyear Ice Cover. J. Clim. 2011, 25, 1176-1193. [CrossRef]

5. Wu, B.; Wang, J.; Walsh, J.E. Dipole Anomaly in the Winter Arctic Atmosphere and Its Association with Sea Ice Motion. J. Clim. 2006, 19, 210-225. [CrossRef]

6. Serreze, M.C.; Stroeve, J.; Barrett, A.P.; Boisvert, L.N. Summer atmospheric circulation anomalies over the Arctic Ocean and their influences on September sea ice extent: A cautionary tale. J. Geophys. Res. Atmos. 2016, 121, 11463-11485. [CrossRef]

7. Ogi, M.; Yamazaki, K.; Tachibana, Y. The summer northern annular mode and abnormal summer weather in 2003. Geophys. Res. Lett. 2005, 32, 353-368. [CrossRef]

8. Ogi, M.; Rysgaard, S.; Barber, D.G. Importance of combined winter and summer Arctic Oscillation (AO) on September sea ice extent. Environ. Res. Lett. 2016, 11, 034019. [CrossRef]

9. Chen, M.; Xu, H.; Guan, Z. Relationship of spring Greenland sea ice with summer surface air temperature and rainfall in China. J. Nanjing Inst. Meteorol. 2001, 24, 483-490.

10. Li, F.; Wang, H. Autumn Sea Ice Cover, Winter Northern Hemisphere Annular Mode, and Winter Precipitation in Eurasia. J. Clim. 2013, 26, 3968-3981. [CrossRef]

11. Honda, M.; Inoue, J.; Yamane, S. Influence of low Arctic sea-ice minima on anomalously cold Eurasian winters. Geophys. Res. Lett. 2009, 36, 262-275. [CrossRef]

12. Liu, J.; Curry, J.A.; Wang, H.; Song, M.; Horton, R.M. Impact of declining Arctic sea ice on winter snowfall. Proc. Natl. Acad. Sci. USA 2012, 109, 4074-4079. [CrossRef] [PubMed]

13. Park, H.; Walsh, J.E.; Kim, Y.; Nakai, T.; Ohata, T. The role of declining Arctic sea ice in recent decreasing terrestrial Arctic snow depths. Polar Sci. 2013, 7, 174-187. [CrossRef]

14. Wu, B.; Jia, W. Possible impacts of winter Arctic Oscillation on Siberian high, the East Asian winter monsoon and sea-ice extent. Adv. Atmos. Sci. 2002, 19, 297-320. 
15. Liu, N.; Lin, L.; Wang, Y.; Kong, B.; Zhang, Z.; Chen, H. Arctic autumn sea ice decline and Asian winter temperature anomaly. Acta Oceanol. Sin. 2016, 35, 36-41. [CrossRef]

16. Kattsov, V.M.; Walsh, J.E.; Chapman, W.L.; Govorkova, V.A.; Pavlova, T.V.; Zhang, X. Simulation and Projection of Arctic Freshwater Budget Components by the IPCC AR4 Global Climate Models. J. Hydrometeorol. 2009, 8, 571-589. [CrossRef]

17. Bintanja, R.; Selten, F.M. Future increases in Arctic precipitation linked to local evaporation and sea-ice retreat. Nature 2014, 509, 479-482. [CrossRef] [PubMed]

18. Peterson, B.J.; Rahmstorf, S. Increasing river discharge to the Arctic Ocean. Science 2002, 298, $2171-2173$. [CrossRef]

19. Screen, J.A.; Simmonds, I. Declining summer snowfall in the Arctic: Causes, impacts and feedbacks. Clim. Dyn. 2012, 38, 2243-2256. [CrossRef]

20. Alexeev, V.A.; Langen, P.L.; Bates, J.R. Polar amplification of surface warming on an aquaplanet in "ghost forcing" experiments without sea ice feedbacks. Clim. Dyn. 2005, 24, 655-666. [CrossRef]

21. Stroeve, J.C.; Serreze, M.C.; Barrett, A.; Kindig, D.N. Attribution of recent changes in autumn cyclone associated precipitation in the Arctic. Tellus Ser. A Dyn. Meteorol. Oceanogr. 2011, 63, 653-663. [CrossRef]

22. Higgins, M.E.; Cassano, J.J. Impacts of reduced sea ice on winter Arctic atmospheric circulation, precipitation, and temperature. J. Geophys. Res. Atmos. 2009, 114, D16107. [CrossRef]

23. Gimenosotelo, L.; Nieto, R.; Vazquez, M.; Gimeno, L. A new pattern of the moisture transport for precipitation related to the drastic decline in Arctic sea ice extent. Earth Syst. Dyn. Discuss. 2018, 9, 611-625. [CrossRef]

24. Ding, Q.; Schweiger, A.; L'Heureux, M.; Battisti, D.S.; Po-Chedley, S.; Johnson, N.C.; Blanchard-Wrigglesworth, E.; Harnos, K.; Zhang, Q.; Eastman, R.; et al. Influence of high-latitude atmospheric circulation changes on summertime Arctic sea ice. Nat. Clim. Chang. 2017, 7, 289-295. [CrossRef]

25. Ogi, M.; Wallace, J.M. Summer minimum Arctic sea ice extent and the associated summer atmospheric circulation. Geophys. Res. Lett. 2007, 34, 107-124. [CrossRef]

26. Zuo, J.; Ren, H.L.; Wu, B.; Li, W. Predictability of winter temperature in China from previous autumn Arctic sea ice. Clim. Dyn. 2016, 47, 2331-2343. [CrossRef]

27. Yang, W.; Magnusdottir, G. Springtime extreme moisture transport into the Arctic and its impact on sea ice concentration. J. Geophys. Res. 2017, 122, 5316-5329. [CrossRef]

28. Pearson, K. Notes on regression and inheritance in the case of two parents. Proc. R. Soc. Lond. 1895, 158, 240-242.

29. Mann, H.B. Nonparametric Tests Against Trend. Econometrica 1945, 13, 245-259. [CrossRef]

30. Kendall, M.G. Rank Correlation Methods; Griffin: Oxford, UK, 1990; p. 108.

31. Panagiotopoulos, F.; Shahgedanova, M.; Hannachi, A.; Stephenson, D.B. Observed trends and teleconnections of the Siberian high: A recently declining center of action. J. Clim. 2005, 18, 1411-1422. [CrossRef]

32. Comiso, J.C.; Meier, W.N.; Gersten, R. Variability and Trends in the Arctic Sea Ice Cover: Results from Different Techniques. J. Geophys. Res. 2017, 122, 6883-6900. [CrossRef]

33. Zhao, J.; Shi, J.; Wang, Z.; Li, Z.; Huang, F. Arctic Amplification Produced by Sea Ice Retreat and Its Global Climate Effects. Adv. Earth Sci. 2015, 30, 985-995.

34. Kumar, A.; Perlwitz, J.; Eischeid, J.; Quan, X.; Xu, T.; Zhang, T.; Hoerling, M.; Jha, B.; Wang, W. Contribution of sea ice loss to Arctic amplification. Geophys. Res. Lett. 2010, 37, 389-400. [CrossRef]

35. Kopec, B.G.; Feng, X.; Michel, F.A.; Posmentier, E.S. Influence of sea ice on Arctic precipitation. Proc. Natl. Acad. Sci. USA 2015, 113, 46-51. [CrossRef] [PubMed]

36. Zhang, P.; Wu, Y.; Simpson, I.R.; Smith, K.L.; Zhang, X.; De, B.; Callaghan, P. A stratospheric pathway linking a colder Siberia to Barents-Kara Sea sea ice loss. Sci. Adv. 2018, 4, eaat6025. [CrossRef]

37. Wu, B.Y.; Su, J.Z.; Zhang, R.H. Effects of autumn-winter Artic sea ice on winter Siberian High. Chin. Sci. Bull 2011, 56, 2335-2343. [CrossRef]

(C) 2019 by the authors. Licensee MDPI, Basel, Switzerland. This article is an open access article distributed under the terms and conditions of the Creative Commons Attribution (CC BY) license (http:/ / creativecommons.org/licenses/by/4.0/). 